\title{
2 Optical coherence tomography for biofilm detection in chronic rhinosinusitis with nasal polyposis
}

\author{
László Tóth · Attila Vajas · Péter Csomor · \\ András Berta $\cdot$ István Sziklai $\cdot$ Tamás Karosi
}

Received: 26 February 2012 / Accepted: 2 May 2012

(C) Springer-Verlag 2012

\begin{abstract}
Chronic rhinosinusitis with nasal polyposis (CRSwNP) is a multifactorial disease that seems to be associated with the presence of microbial biofilms and corresponding subepithelial inflammatory reactions. Optical coherence tomography (OCT) might be applied to detect bacterial and fungal biofilms in patients with CRSwNP. A total of 27 patients with CRSwNP undergoing endoscopic sinus surgery (ESS) were analyzed. The negative control group consisted of six patients undergoing septoplasty for nasal obstruction without CRSwNP. The nasal polyps and inferior turbinate mucosa specimens applied as negative controls were processed to OCT analysis and H.E. and Gram staining. Biofilm was detected in 22 of 27 patients $(81.5 \%)$ with CRSwNP and in none of six negative controls. In our series, OCT scan showed an obvious association with the findings of H.E. and Gram staining and was allocated to be a good predictor of biofilm existence. On OCT images, biofilms were displayed as distinct superficial layers with high optical density. It was found that microscopic architecture of biofilms was strongly associated with the integrity of nasal mucosa and to the cellular pattern of subepithelial inflammatory reaction. This study confirmed the presence of microbial biofilms in patients with CRSwNP according to OCT scans and histological analysis. Since biofilms may affect the severity and recurrence
\end{abstract}

L. Tóth $(\varangle) \cdot$ P. Csomor $\cdot$ I. Sziklai $\cdot$ T. Karosi

Department of Otolaryngology and Head and Neck Surgery,

Medical and Health Science Center, University of Debrecen,

Nagyerdei Krt. 98., 4032 Debrecen, Hungary

e-mail: karositamas@gmail.com

URL: www.earpathology.eu

A. Vajas $\cdot$ A. Berta

Department of Ophthalmology, Medical and Health Science

Center, University of Debrecen, Debrecen, Hungary rate of CRS treated by ESS they should be detected preoperatively. In conclusion, single application of OCT analysis or combination with conventional histological protocols provides a robust and reliable method for the detection of bacterial and fungal biofilms in CRSwNP. Level of evidence $3 \mathrm{~b}$, individual case-control study.

Keywords Biofilm · Chronic rhinosinusitis · Gram staining $\cdot$ Hematoxylin-eosin staining $\cdot$ Nasal polyps . Optical coherence tomography

\section{Introduction}

Chronic rhinosinusitis (CRS) is a common inflammatory disease with heterogeneous background [1, 2]. In rhinological practice, CRS is responsible for a great amount of medical visits and one of the main reasons for antibiotic treatment and sick leave [1]. Beyond physical examination and coronal reconstructed CT scans, diagnosis of CRS is based on the duration of symptoms (nasal obstruction, olfactory dysfunction, discharge and pain), which persist over 3 months [1]. CRS with nasal polyposis (CRSwNP) is a separate diagnostic entity, which is currently thought to be a complex immunological disease affected by multiple factors [1]. These are immunological disorders, bronchial asthma, aspirin intolerance, ASA-syndrome, genetic diseases (cystic fibrosis, Kartagener's disease), Staphylococcus superantigens, and fungal infections [1-3]. Recently, bacterial and fungal biofilms with consecutive inflammatory reactions have been suspected to be the main etiologic factors of nasal polyp formation in CRS [2, 4-6].

Biofilms have been implicated in the pathogenesis of various chronic inflammatory diseases, which affects mucosal surfaces [7, 8]. This group of infectious diseases

\begin{tabular}{|l|l|c|l|llll|}
\hline Large 405 & 2051 & xxxx & \multicolumn{2}{|l|}{ Dispatch: 8.5.12 } & \multicolumn{2}{c|}{ No. of Pages: 9 } \\
\hline Journal & Article & MS Code & LE $\square$ & TYPESET $\square$ & CP $\square$ & DISK $\square$ \\
\hline
\end{tabular}


includes chronic tonsillitis, adenoiditis, CRS with or without nasal polyposis, chronic otitis media, periodontitis, chronic prostatitis, and chronic pelvic inflammatory disease [7-10]. Furthermore, presence of biofilms could be a great therapeutic problem on the surface of different surgical implants, which might be responsible for antibiotic- and antimycotic-resistant postoperative infections [11].

Bacterial- and fungal colonies exist as free planktonic prokaryote- or eukaryote cells or as complex biofilm webs $[2,7]$. Biofilm formation provides a great evolutionary advantage for bacterial- or fungal survival and proliferation $[2,7]$. Biofilms are characterized by a self-produced threedimensional extracellular matrix that consists of water, polysaccharides, proteins, and nucleic acids [7,9]. This complex structure provides extremely high resistance against antimicrobial agents and host immune reactions $[6$, $7,12]$. This resistance mechanism is based on the physical barrier formed by the polysaccharide matrix that blocks the diffusion of antibiotics, antimycotics, superoxides, immunglobulins, and opsonins $[6,7,12]$. Biofilms can be formed by individual- or mixed species of bacteria and fungi that usually cannot be cultured and isolated by conventional microbiological protocols; therefore, diagnosis is often uncertain $[2,7,8]$. Nevertheless, biofilms can be detected by difficult, expensive, and time-consuming protocols of scanning electron microscopy (SEM), transmission electron microscopy (TEM), confocal laser scanning microscopy (CLSM), and recently by microbe-specific fluorescent in situ hybridization (FISH) [8, 13, 14]. Hochstim et al. [15] have reported a robust method for biofilm detection that was based on the conventional hematoxylin-eosin (H.E.) staining of fresh surgical specimens obtained from patients with CRSwNP. Later, Tóth et al. [16] have reported a reliable protocol for bacterial- and fungal biofilm detection that was based on the combination of H.E. and Gram staining of nasal polyps obtained from patients with CRS.

Optical coherence tomography (OCT) is a complex optical signal processing method that provides a micrometer scale resolution and two- or three-dimensional images from different tissues [17]. Depending on the physical properties of OCT device and the refinement of processing method, the image resolution can achieve the quality of a real histological slide [17, 18]. OCT is based on the optical interferometry, typically using near-infrared light $[17,18]$. The basic two-dimensional images are processed by fast Fourier-transformation (FFT) of the collected light reflection and absorption data $[17,18]$. The relatively long wavelength light allows a $1-2 \mathrm{~mm}$ penetration into the scattering medium, because at greater depths, a large amount of emitted light escapes without scattering and reflection [17]. The commercially available OCT systems are employed in diverse applications, including diagnostic medicine, mainly in ophthalmology where it can be applied to obtain highly detailed images from the retinal layers [18]. OCT has also begun to be introduced into interventional cardiology to diagnose the severity of coronary artery disease and atherosclerosis [19]. Recently, potential applications of OCT have been reported in several fields of ENT practice [20, 21]. OCT seems to be a reliable method to predict the outcomes of cochlear implant surgery by the intraoperative visualization of the fine structures of cochlea and spiral ganglion $[22,23]$. Furthermore, OCT has been reported to be a helpful method in different laryngological applications, especially in the evaluation of laryngeal cancer and its precursor lesions $[24,25]$. In the phoniatric practice, OCT has been found to be a highly sophisticated method in the assessment of shape, amplitude, and velocity of vocal fold mucosal waves providing biomechanical characteristics of vocal folds with various laryngeal pathologies [26, 27]. Finally, OCT has been reported to be a robust method in the prediction of the severity of postintubation upper airway stenosis in children by the assessment of submucosal fibrosis $[28,29]$.

This study investigates the presence and microscopic characteristics bacterial-, fungal- and combined biofilms in CRSwNP. Findings of conventional histological analysis were correlated to those of OCT scans with the aim to confirm the availability of OCT in biofilm detection.

\section{Materials and methods}

Patients with CRSwNP and healthy controls

We performed a case-control experimental study on nasal polyps obtained from patients with CRSwNP who underwent ESS at the Department of Otorhinolaryngology and Head and Neck Surgery, University of Debrecen. Nasal polyp specimens were collected between April and August 2011. The patient group consisted of 11 women and 16 men ( $n=27$, mean age $=42.19$ years; range $=23-71$ years $)$ with CRSwNP. Diagnosis was based on nasal endoscopy and computed tomography (CT) scan of paranasal sinuses. The Lund-Mackay scores of coronal reconstructed CT scans varied between 11 and 24 with an average score of 20 indicating massive involvement of paranasal sinuses by CRS. The score was higher than 20 in $66.6 \%$ of patients $(n=18)$. The clinical history and findings of physical examinations were obtained from each patient. Clinical information on bronchial asthma, allergic rhinitis, aspirin intolerance, ASA-triad, previous ESS, topical steroid treatment, and systemic antibiotic therapy was recorded before surgical intervention. Three patients $(11.1 \%)$ had bronchial asthma, $14.8 \%(n=4)$ had allergic rhinitis, and $3.7 \%(n=1)$ had the diagnosis of aspirin intolerance and ASA triad (nasal polyposis, bronchial asthma and aspirin intolerance). Dsiagnosis of allergic

\begin{tabular}{|c|c|c|c|c|c|c|}
\hline Large 405 & 2051 & $\mathbf{x x X X}$ & Dispatc & 5.12 & & of Pages: 9 \\
\hline Journal & Article & MS Code & LE $\square$ & TYPESET $\square$ & CP $\square$ & DISK $\square$ \\
\hline
\end{tabular}


Table 1 Clinical history of patients with CRSwNP

\begin{tabular}{llllllll}
\hline $\begin{array}{l}\text { Number of } \\
\text { patients }\end{array}$ & $\begin{array}{l}\text { Bronchial } \\
\text { asthma }\end{array}$ & $\begin{array}{l}\text { Allergic } \\
\text { rhinitis }\end{array}$ & $\begin{array}{l}\text { Aspirin } \\
\text { intolerance }\end{array}$ & $\begin{array}{l}\text { Average } \\
\text { Lund-Mackay score }\end{array}$ & Previous ESS & $\begin{array}{l}\text { Topical steroid } \\
\text { treatment }\end{array}$ & $\begin{array}{l}\text { Systemic } \\
\text { antibiotic treatment }\end{array}$ \\
\hline 27 & $3(11.1 \%)$ & $4(14.8 \%)$ & $1(3.7 \%)$ & $20(11-24)$ & $8(29.6 \%)$ & $27(100 \%)$ & $4(14.8 \%)$ \\
\hline
\end{tabular}
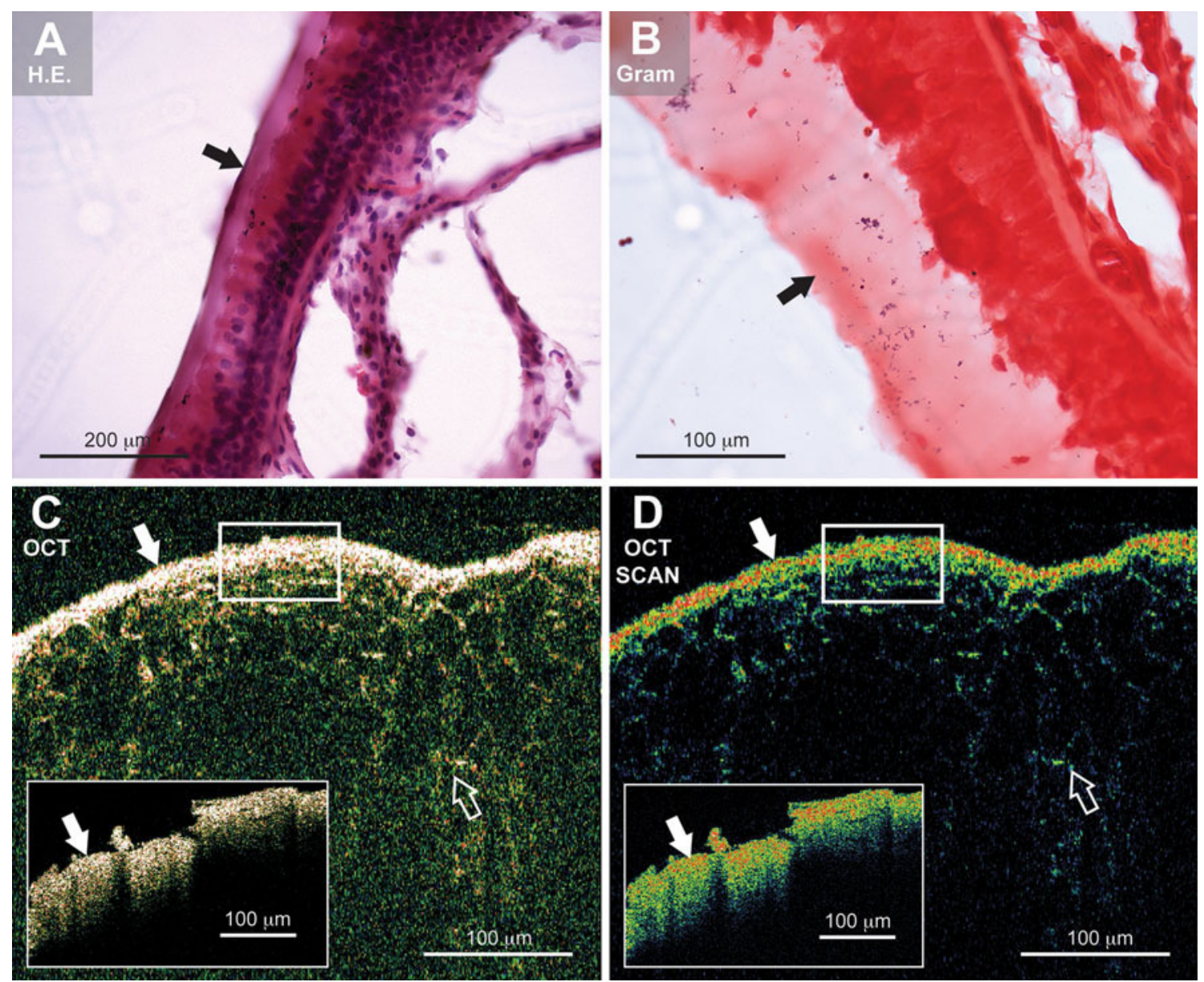

Fig. 1 Histopathological and OCT analysis of a nasal polyp. a H.E. staining shows a regular columnar epithelium with well-defined basal lamina. On the surface of nasal epithelium, a dense and homogeneously basophilic layer of $70 \mu \mathrm{m}$ thickness can be detected (black arrow). b Gram staining indicates a bacterial biofilm consisted of individual colonies Gram-positive cocci (black arrow). c OCT analy-

166 rhinitis was based on the clinical history and on the allergen-

167 specific intracutan test. In some cases inhalative allergen-spe-

168 cific serum IgE levels were also measured by ELISA. The

169 diagnosis of bronchial asthma was based on the clinical his-

170 tory and on the respiratory functional test. The diagnosis was

171 stated by an experienced pulmonologist in all cases. Aspirin

172 intolerance was based on the presence of aspirin-induced

173 hypersensitive reaction in the clinical history of the patients.

174 Repeated ESS was performed in $29.6 \%(n=8)$ of patients,

175 which is suspected to be an important predictive factor of dis-

176 ease recurrence. In this group, number of previous surgeries

177 varied between 1 and 12 with an average number of 3.7 ESS. sis reveals three distinct layers of nasal polyp: a superficial, glittering layer indicating biofilm (small insert and white arrows); a middle layer of respiratory epithelium with honey-comb structure (white, empty arrow); and a deep homogeneous layer of submucosa. d Scanned OCT image reveals quite similar structure with decreased digital noise

All patients were treated by topical mometasone furoate monohydrate $\left(200 \mu \mathrm{g} / \mathrm{day}\right.$, Nasonex ${ }^{\mathrm{TM}}$, Merck-ScheringPlough-Merger, USA) therapy before surgery. The average period of intranasal steroid treatment was 22.7 months that varied between 8 and 49 months. Preoperative, systemic antibiotic treatment was performed in $4(14.8 \%)$ patients due to recurring acute rhinosinusitis. Table 1 summarizes the clinical history of patients with CRSwNP. All the nasal polyps collected during ESS were processed to histopathological and OCT analysis. Only nasal polyps larger than $2 \mathrm{~cm}$ were analyzed that could be removed by a straight ESS-forceps without any surface injury or iatrogenic disruption of biofilm

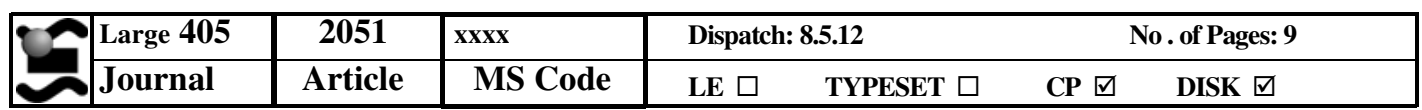



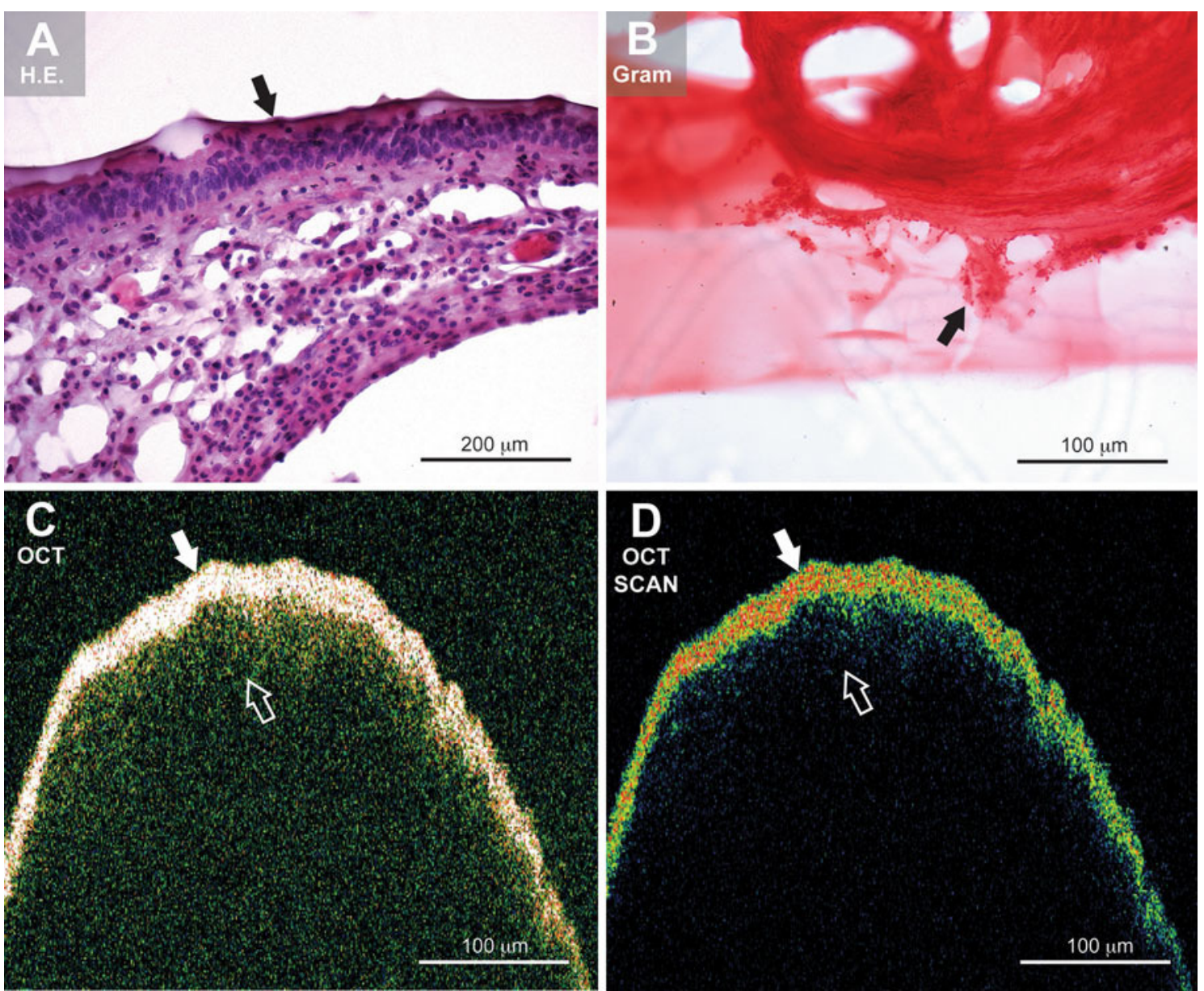

Fig. 2 Histopathological and OCT examination of a nasal polyp. a The epithelial layer is destructed, basal lamina is fragmented, while the stromal layer is full-filled by plasmocytes and polymorphonuclear cells (H.E.). The mucosa is covered by a complete biofilm showing basophilic staining (black arrow). b Gram staining reveals a bacterial

layers. The removal was gently performed at the origin of nasal polyps. Six patients $(n=6$; men $=5$; women $=1$; mean age $=41.27$ years) scheduled for septoplasty for nasal obstruction without CRS were recruited into the negative control group. Tissue specimens of approximately $0.2 \mathrm{~cm}^{3}$ were obtained from the anterior third of the inferior turbinate. All patients gave their informed consent before donating their tissue samples for the study. We obtained Institutional Ethical Committee (DE OEC-EB/2009/12) approvals. The study was carried out according to the Declaration of Helsinki.

\section{Optical coherence tomography analysis}

After ESS of CRSwNP patients and septoplasty of negative controls, a total of 33 nasal mucosa specimens were immediately stored in $0.9 \%(\mathrm{w} / \mathrm{v})$ sodium-chloride solution $\left(4{ }^{\circ} \mathrm{C}\right.$, $1 \mathrm{~h}$ ) until OCT analysis. Individual nasal polyp specimens biofilm consisted of individual colonies of Gram-negative cocci (black arrow). c OCT analysis also reveals the three layers of biofilm (white arrow), mucosa (empty white arrow) and submucosa. d Scanned OCT image indicates similar pattern of tissue layers and represents biofilm as a quite dense structure of $40 \mu \mathrm{m}$ thickness (white arrow) were placed on a self-designed silicone mount in front of the OCT device. A commercially available clinical imaging system (Zeiss Straus OCT-3, Karl Zeiss INC, Jena, Germany) powered by Zeiss OCT 6.0 software was used to examine each samples. This OCT system uses a low-coherence nearinfrared light source of $850 \mathrm{~nm}$ to acquire images of $250 \times 250$ pixels at a maximum frame rate of $0.7 \mathrm{~Hz}$. The spatial depth resolution of the system is $10-20 \mu \mathrm{m}$, with a depth scanning range of $2.5 \mathrm{~mm}$. In practice, owing to the turbidity of fresh tissues, scanning depth is only about $2 \mathrm{~mm}$. The lateral resolution is $20 \mu \mathrm{m}$, with a lateral scanning range of $2.55-3.87 \mathrm{~mm}$. In this OCT setup, lateral resolution is diffraction limited, whereas axial resolution depends on the coherence length of the light source. Images were archived in .pdf file format as two-dimensional B-scans in cross-hair scan mode of the OCT system. OCT scans were blinded for two independent researchers: A.V. performed the examinations, while L.T. concluded the OCT results.

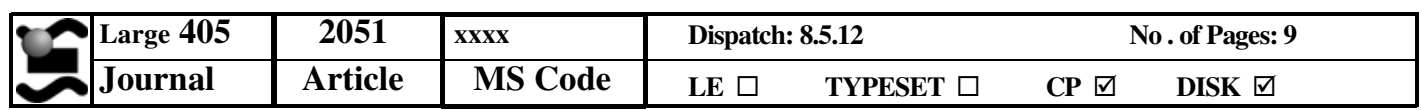



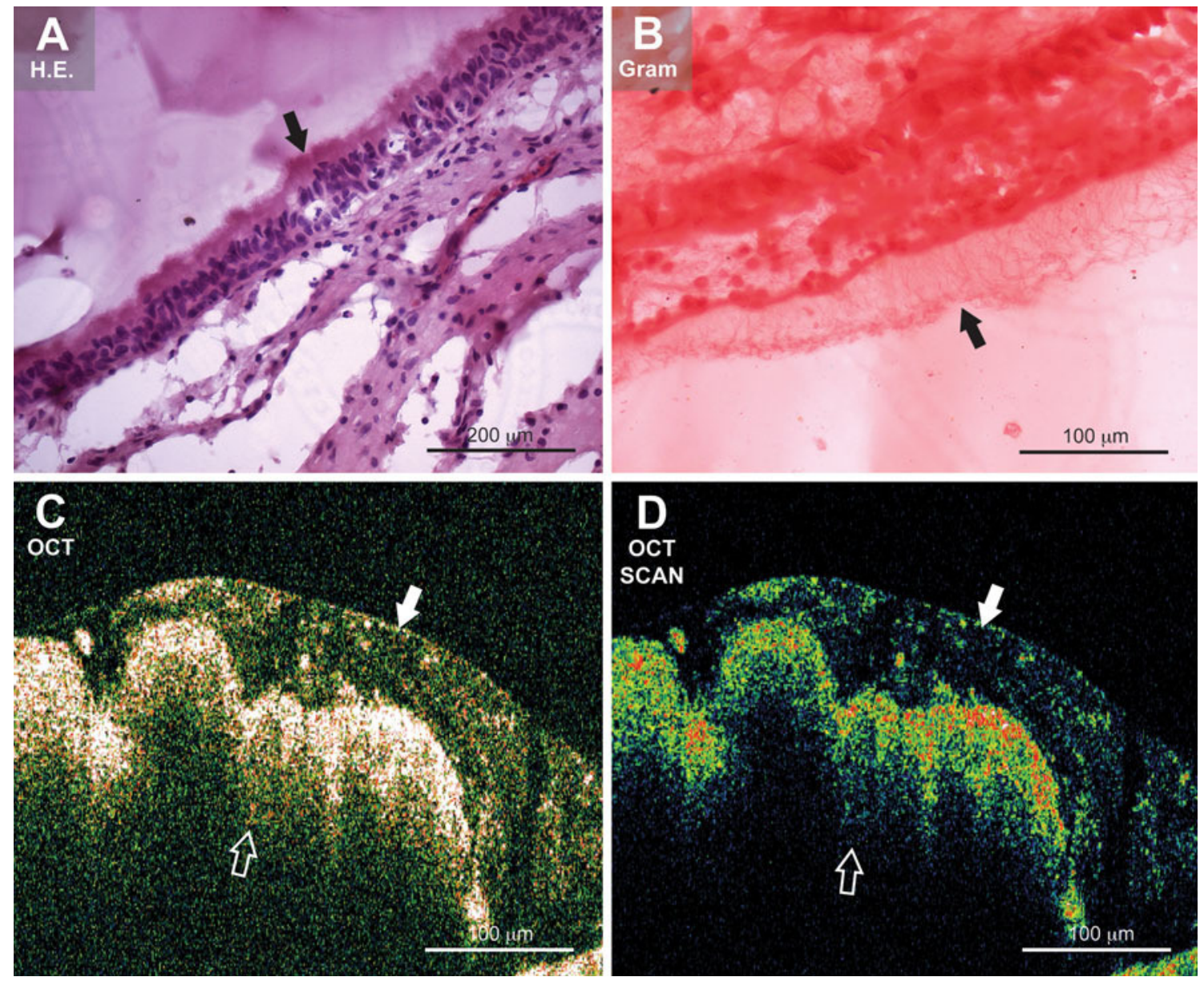

Fig. 3 Histopathological representation and OCT scan of a nasal polyp. a The architecture of epithelium is destructed; foamy cells are missing (H.E.). The submucosal layer is predominantly infiltrated by plasmocytes. The mucosa is covered by a thick and deranged biofilmlike structure (black arrow). b Gram staining indicates a fungal biofilm with Gram-negative tangled web of fungal mycelia (black arrow).

\section{Histopathological analysis}

After OCT analysis, a total of 33 nasal mucosa specimens were fixed in $10 \%(\mathrm{w} / \mathrm{v})$ formaldehyde. Specimens were embedded in $15 \%(\mathrm{w} / \mathrm{v})$ purified gelatin $\left(24 \mathrm{~h}, 56^{\circ} \mathrm{C}\right)$ and refixed in $4 \%(\mathrm{w} / \mathrm{v})$ paraformaldehyde $\left(24 \mathrm{~h}, 20^{\circ} \mathrm{C}\right)$. Blocks were cryoprotected in $20 \%$ (w/v) sucrose-solution $\left(2 \mathrm{~h}, 4{ }^{\circ} \mathrm{C}\right)$ and sectioned into $5 \mu \mathrm{m}$ slides at $-25^{\circ} \mathrm{C}$ (MNT-200, Slee, Mainz, Germany). Slides were stored in $0.1 \mathrm{M}$ PBS containing $0.03 \%(\mathrm{w} / \mathrm{v})$ sodium-azide at $4{ }^{\circ} \mathrm{C}$. Two consecutive $5 \mu \mathrm{m}$ frozen cut sections were examined as follows: (1) conventional staining with hematoxylin and eosin (H.E.); and (2) conventional Gram staining. Histological pretreatment protocol was performed by an independent laboratory assistant. Histological examinations were blinded for two independent researchers: P.Cs. analyzed the sections stained by H.E., while T.K. examined the results of Gram staining. The criteria for the histopathological detec- c OCT analysis represents fungal biofilm as a duplicate structure consisted of superficial foamy- and deeper and dense glittering layers (white arrow). The border of epithelium and submucosa is displayed by empty white arrow. d Scanned OCT image reveals quite similar structure with decreased digital noise

tion of bacterial and also fungal or combined biofilms were the presence of characteristic morphology and Gram positivity/negativity and micro colonies for examination by optical microscopy and the presence of the surrounding polysaccharide layer. Structure and cellular infiltration of the epithelial- and also the subepithelial layers were correlated to the presence or absence of bacterial or fungal biofilms.

\section{Results}

Altogether 27 patients with CRSwNP who underwent ESS were included in this study. The histopathological examination revealed inflammatory nasal polyps with eosinophilic, polymorphonuclear, and plasmocyte infiltration of the subepithelial layer in all cases. Bacterial- $(n=15)$, fungal$(n=5)$ or combined $(n=2)$ biofilms were detected in 22
250 251 252 253 254 255

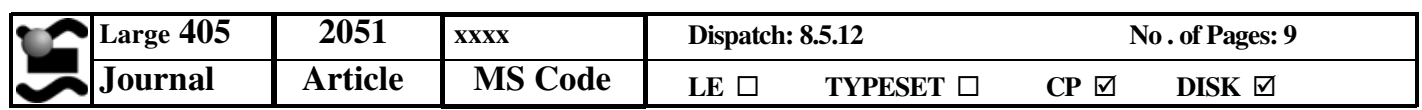



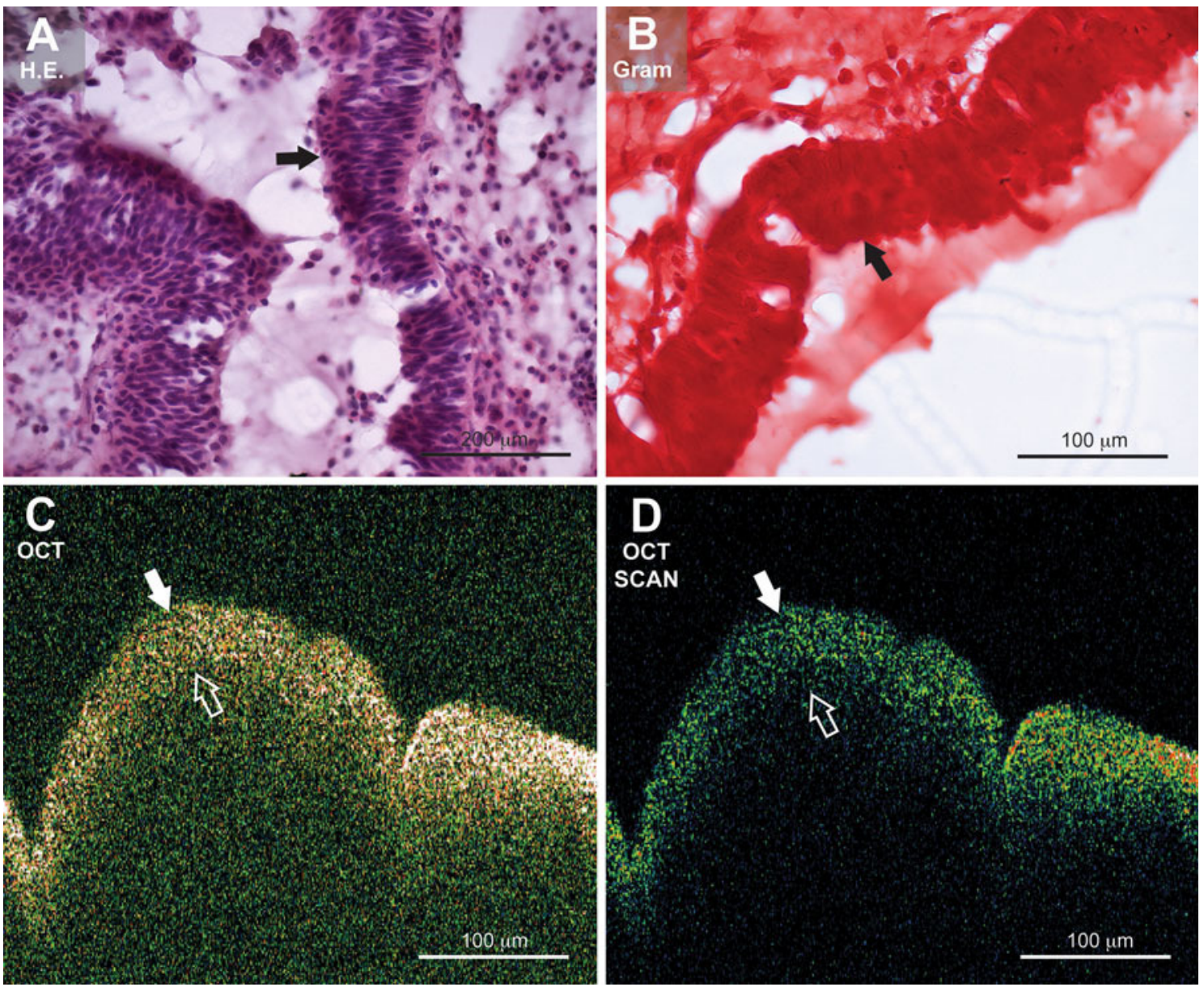

Fig. 4 Histopathological analysis and OCT scan of a nasal polyp. a H.E. staining indicates a well-organized respiratory epithelium (black arrow) with prominent basal lamina. The submucosal layer is predominantly infiltrated by eosinophils. Biofilm structures cannot be detected on the surface of nasal epithelium. b Gram staining is negative for bacterial or fungal elements; the polysaccharide matrix is

$256(81.5 \%)$ of 3627 patients with CRSwNP (Figs. 1, 2, 3; 257 Table 2). In the biofilm-negative cases $(n=5,18.5 \%)$, his258 topathological analysis revealed well-organized columnar 259 epithelium with predominantly eosinophilic and lympho260 cyte infiltration of the subepithelial layer (Fig. 4; Table 2). 261 Furthermore, predominant eosinophilic infiltration of the 262 subepithelial layer decreased the chance of biofilm detec263 tion. All patients diagnosed with allergic rhinitis $(n=4$, $26414.8 \%$ ) were recruited into the biofilm negative group $265(n=5)$ and $80 \%$ of biofilm-negative specimens were 266 obtained from patients with allergic rhinitis (Table 2). 267 Since our patients were all treated by topical steroids, this 268 finding seems to be associated with the diagnosis of allergic 269 rhinitis itself. In our series, H.E. staining displayed a strong 270 correlation with the results of Gram staining and no dis271 crepancies were found between the two staining protocols 272 (Table 2). Disintegration or metaplasia of the respiratory 273 epithelium due to subepithelial inflammatory reactions was 274 strong predictor of biofilm detection (Figs. 1, 2, 3; Table 2). absent (black arrow). c OCT examination displays two layers of epithelium (white arrow) and submucosa. The border between these structures is indicated by empty white arrow. The superficial glittering suspecting microbial biofilm is missing. d Scanned OCT image reveals quite similar pattern due to decreased digital noise

Among biofilm-positive cases, polymorphonuclear infiltration of the stromal layer was found to be the most important factor of biofilm presence (Figs. 1, 2, 3; Table 2). All OCT scans were reviewed by the authors with 26 agreements (96.3\%) of the 27 histopathological findings for biofilm detection (Table 2). The OCT scan with doubtful result for biofilm detection was individually recruited into the biofilm-negative group (Table 2). OCT scans showed good correspondence to the histopathological findings with $100 \%$ agreements of biofilm-negative cases and $95.45 \%$ agreements of biofilm-positive specimens (Table 2). According to OCT scans, biofilms were represented as 20to $100-\mu \mathrm{m}$-thick superficial glittering dense structures, what correlated fully with the results of histopathological analysis (Figs. 1, 2, 3). The respiratory epithelium, the subepithelial layer, and if present, biofilm layer were well identifiable structures by OCT scan correlated to histopathological examinations (Figs. 1, 2, 3, 4). No biofilm-like structures were detected in mucosal specimens obtained from the

\begin{tabular}{|c|c|c|c|c|}
\hline Large 405 & 2051 & $\mathbf{x x x x}$ & Dispatch: 8.5.12 & No. of Pages: 9 \\
\hline Journal & Article & MS Code & TYPESET $\square$ & DISK 曰 \\
\hline
\end{tabular}



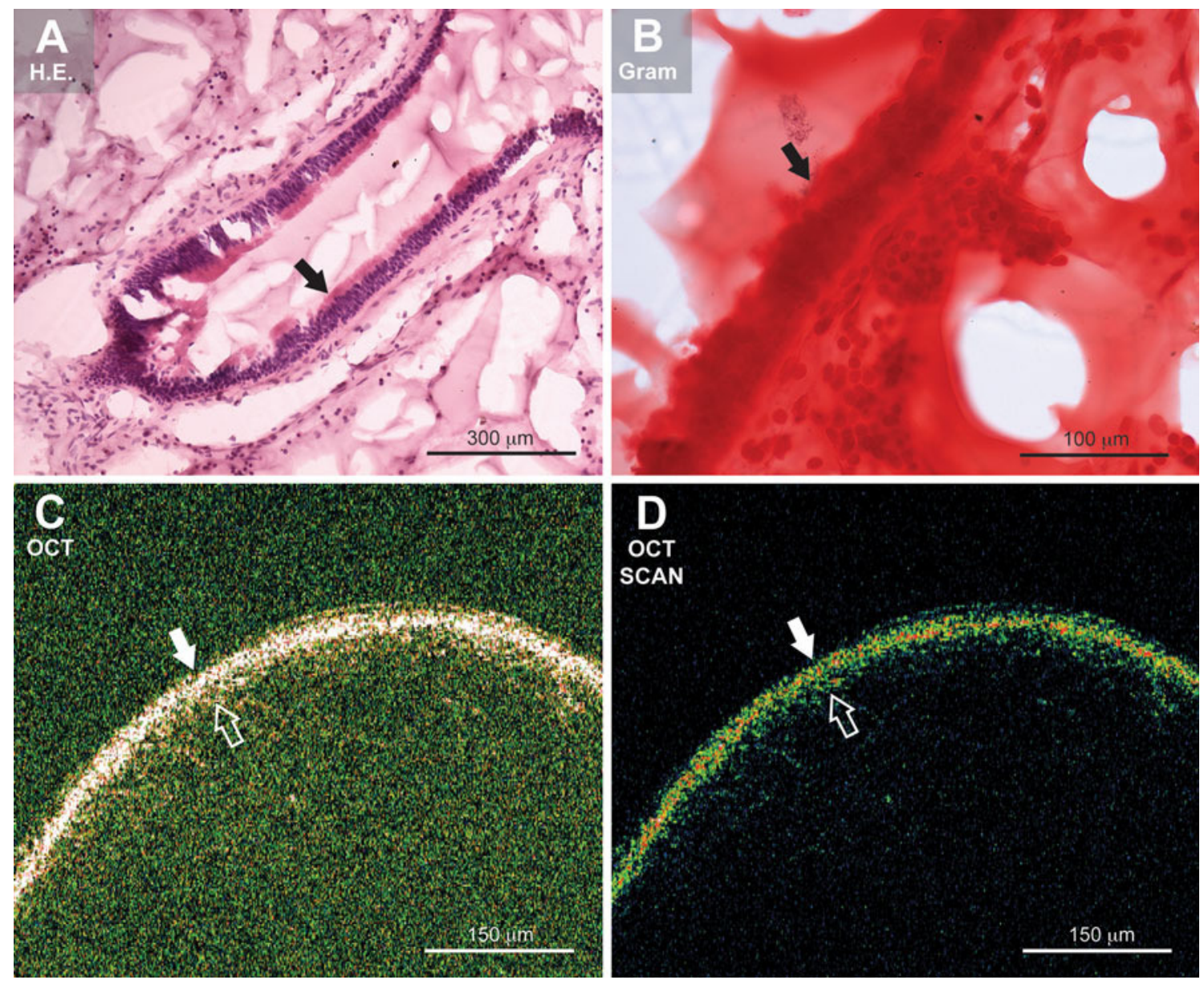

Fig. 5 Histopathological analysis and OCT scan of an inferior turbinate specimen applied as negative control. a H.E. staining represents a normal columnar epithelium with prominent ciliar layer (black arrow). The amount of inflammatory cells in the submucosal layer is relatively less in comparison to NP samples. b Gram staining is negative for bac-

terial or fungal elements (black arrow). c OCT picture displays two distinct layers of epithelium and submucosa (white- and empty white arrows) without manifest signs for biofilm presence. d Scanned OCT image shows the same architecture

Table 2 Biofilm detection by conventional histological methods correlated to optical coherence tomography

\begin{tabular}{llc}
\hline & Nasal polyps $(n=27)$ H.E. and Gram staining & Biofilm present $(n=22,81.5 \%)$ \\
\cline { 2 - 3 } & Biofilm absent $(n=5,18.5 \%)$ & 21 \\
OCT positivity & 0 & Destructed or metaplastic mucosa \\
Epithelium & $\begin{array}{c}\text { Regular columnar epithelium with ciliated } \\
\text { and foamy cells }\end{array}$ & $\begin{array}{c}\text { Polymorphonuclear and plasmocyte } \\
\text { predominancy }\end{array}$ \\
\hline
\end{tabular}

OCT Optical coherence tomography

294 inferior turbinate of patients $(n=6)$ applied as negative

295 controls.

\section{Discussion}

297 In the present study, we demonstrated the presence of 298 biofilms in 21 patients with CRSwNP by the combined application of H.E. and Gram staining protocols and OCT analysis. Furthermore, absence of biofilms was not associated to the single employment of histopathological staining protocols or OCT scans.

CRSwNP is a disease of multifactorial agents involving disturbed local immune response and chronic inflammation; however, biofilms might contribute to the damage of respiratory epithelium and subsequent hyperplasia of the
299

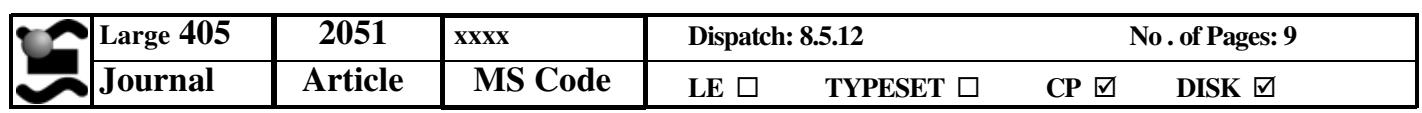


307 subepithelial layer infiltrated by inflammatory cells $[2,6$, 308 12]. Although specific treatments are not available to target 309 biofilms, it is very important to be detected, since it is 310 strongly associated with treatment failure and persisting 311 symptoms [1, 2, 30]. Since biofilms are thought to play a 312 crucial role in the pathogenesis of CRSwNP, our aim was 313 to provide a simple, rapid and reliable method for microbial 314 biofilm detection (Fig. 5).

315 The main goal was not the precise identification of 316 bacterial or fungal species, because presence of biofilm 317 itself is suspected to be the most important factor in the 318 pathogenesis of CRSwNP [2, 4, 8]. Furthermore, persist319 ing biofilms in CRSwNP cases may be responsible for 320 surgical failures and high recurrence rate of disease [1, 321 2]. Microbiological identification of different bacterial 322 and fungal species involved in biofilm formation still 323 requires electron microscopic- or FISH analysis with spe324 cies-specific oligonucleotide probes $[8,13,14]$. In the 325 light of our results, we do think that combination of H.E. 326 and Gram staining protocols and OCT scans should be 327 emphasized. Since H.E. staining is for the investigation 328 of tissue architecture while Gram protocol stains micro329 bial elements, combination with morphological images 330 of OCT systems might have higher diagnostic power for 331 biofilm detection in CRSwNP. According to recently 332 published data of Hochstim et al., we have also con333 firmed that the wide availability of H.E. and Gram stain334 ing through routine histopathology laboratories makes 335 this a reliable method for detection of biofilms in the 336 clinical practice $[15,16]$.

337 The main disadvantage of OCT is that acquisition of a 338 device requires relatively high cost of a single investment 339 of approximately 70.000 USD (53.000-300.000) that usu340 ally exceeds the budget of a general ENT department [18, 341 19]. This problem; however, could be solved by the collab342 oration with ophthalmology departments and outpatient 343 wards, where OCT supplies as a routine imaging tool of ret344 inal diseases and vascular disorders [18]. The other solution 345 is the establishment of core facilities within the institute 346 that are able to supply OCT setups in a rental system. The 347 key beneficial features of OCT are that it provides live sub348 surface images at near-microscopic resolution, instant and 349 direct imaging of tissue morphology and it employs non350 ionizing radiation [17, 18]. Furthermore, no special pre351 treatment of a biological specimen is required and images 352 can be obtained as non-contact scans or through a transpar353 ent membrane [18]. It is also important to note that the laser 354 radiation from the devices is low-eye-safe near-infra-red 355 light is applied - and no damage to the sample is therefore 356 likely $[17,18]$. Other OCT applications, for example three357 dimensional imaging and flexible OCT probes might 358 improve the diagnostic ability of OCT systems in biofilm 359 detection and visualization [18]. In the future, we would like to test these applications with the aim to introduce an in vivo biofilm detection protocol in CRSwNP.

\section{Conclusion}

In conclusion, further examinations are required to clarify the etiologic role of biofilms in the pathogenesis of CRSwNP. According to current results, OCT seems to be a reliable and robust method for biofilm detection that may contribute to improve new therapeutic options in the treatment of patients with CRSwNP.

363 364 365 366 367 368

Acknowledgments This work was supported by the grant of Hungarian Scientific Research Fund (OTKA PD75371, K81480).

Conflict of interest All authors state that they have no conflicts of interest. Authors declare that Tamás Karosi MD PhD and István Sziklai MD DSc are both considered as last authors of the manuscript.

\section{References}

1. Marple BF, Stankiewicz JA, Baroody FM, Chow JM, Conley DB, Corey JP, Ferguson BJ, Kern RC, Lusk RP, Naclerio RM, Orlandi RR (2009) American Academy of Otolaryngic Allergy Working Group on Chronic Rhinosinusitis. Diagnosis and management of chronic rhinosinusitis in adults. Postgrad Med 121(6):121-139

2. Al-Mutairi D, Kilty SJ (2011) Bacterial biofilms and the pathophysiology of chronic rhinosinusitis. Curr Opin Allergy Clin Immunol 11(1):18-23

3. Healy DY, Leid JG, Sanderson AR, Hunsaker DH (2008) Biofilms with fungi in chronic rhinosinusitis. Otolaryngol Head Neck Surg 138(5):641-647

4. Zernotti ME, Angel Villegas N, Roques Revol M, Baena-Cagnani CE, Arce Miranda JE, Paredes ME, Albesa I, Paraje MG (2010) Evidence of bacterial biofilms in nasal polyposis. J Investig Allergol Clin Immunol 5:380-385

5. Mladina R, Poje G, Vuković K, Ristić M, Musić S (2008) Biofilm in nasal polyps. Rhinology 46(4):302-307

6. Hekiert AM, Kofonow JM, Doghramji L, Kennedy DW, Chiu AG, Palmer JN, Leid JG, Cohen NA (2009) Biofilms correlate with TH1 inflammation in the sinonasal tissue of patients with chronic rhinosinusitis. Otolaryngol Head Neck Surg 141(4):448-453

7. Suh JD, Ramakrishnan V, Palmer JN (2010) Biofilms. Otolaryngol Clin North Am 43(3):521-530

8. Foreman A, Psaltis AJ, Tan LW, Wormald PJ (2009) Characterization of bacterial and fungal biofilms in chronic rhinosinusitis. Am J Rhinol Allergy 23(6):556-561

9. Foreman A, Wormald PJ (2010) Different biofilms, different disease? A clinical outcomes study. Laryngoscope 120(8):17011706

10. Ferguson BJ, Stolz DB (2005) Demonstration of biofilm in human bacterial chronic rhinosinusitis. Am J Rhinol 19(5):452-457

11. Perloff JR, Palmer JN (2004) Evidence of bacterial biofilms on frontal recess stents in patients with chronic rhinosinusitis. Am J Rhinol 18(6):377-380

12. Galli J, Calò L, Ardito F, Imperiali M, Bassotti E, Passali GC, La Torre G, Paludetti G, Fadda G (2008) Damage to ciliated epithelium in chronic rhinosinusitis: what is the role of bacterial biofilms? Ann Otol Rhinol Laryngol 117(12):902-908
375

\begin{tabular}{|c|c|c|c|c|c|c|}
\hline Large 405 & 2051 & $\mathbf{x x X X}$ & Dispatc & 5.12 & & of Pages: 9 \\
\hline Journal & Article & MS Code & LE $\square$ & TYPESET $\square$ & CP $\square$ & DISK $\square$ \\
\hline
\end{tabular}


13. Mladina R, Skitarelić N, Musić S, Ristić M (2010) A biofilm exists on healthy mucosa of the paranasal sinuses: a prospectively performed, blinded, scanning electron microscope study. Clin Otolaryngol 35(2):104-110

14. Psaltis AJ, Ha KR, Beule AG, Tan LW, Wormald PJ (2007) Confocal scanning laser microscopy evidence of biofilms in patients with chronic rhinosinusitis. Laryngoscope 117(7):1302-1306

15. Hochstim CJ, Choi JY, Lowe D, Masood R, Rice DH (2010) Biofilm detection with hematoxylin-eosin staining. Arch Otolaryngol Head Neck Surg 136(5):453-456

16. Tóth L, Csomor P, Sziklai I, Karosi T (2011) Biofilm detection in chronic rhinosinusitis by combined application of hematoxylineosin and gram staining. Eur Arch Otorhinolaryngol 268(10):1455-1462

17. Huang D, Swanson EA, Lin CP, Schuman JS, Stinson WG, Chang W, Hee MR, Flotte T, Gregory K, Puliafito CA et al (1991) Optical coherence tomography. Science 254(5035):1178-1181

18. Gabriele ML, Wollstein G, Ishikawa H, Kagemann L, Xu J, Folio LS, Schuman JS (2011) Optical coherence tomography: history, current status, and laboratory work. Invest Ophthalmol Vis Sci 52(5):2425-2436

19. Prati F, Jenkins MW, Di Giorgio A, Rollins AM (2011) Intracoronary optical coherence tomography, basic theory and image acquisition techniques. Int J Cardiovasc Imaging 27(2):251-258

20. Wong BJ, Zhao Y, Yamaguchi M, Nassif N, Chen Z, De Boer JF (2004) Imaging the internal structure of the rat cochlea using optical coherence tomography at 0.827 microm and 1.3 microm. Otolaryngol Head Neck Surg 130(3):334-338

21. Choudhury N, Song G, Chen F, Matthews S, Tschinkel T, Zheng J, Jacques SL, Nuttall AL (2006) Low coherence interferometry of the cochlear partition. Hear Res 220(1-2):1-9
22. Lin J, Staecker H, Jafri MS (2008) Optical coherence tomography imaging of the inner ear: a feasibility study with implications for cochlear implantation. Ann Otol Rhinol Laryngol 117(5):341-346

23. Pau HW, Lankenau E, Just T, Behrend D, Hüttmann G (2007) Optical coherence tomography as an orientation guide in cochlear implant surgery? Acta Otolaryngol 127(9):907-913

24. Hughes OR, Stone N, Kraft M, Arens C, Birchall MA (2010) Optical and molecular techniques to identify tumor margins within the larynx. Head Neck 32(11):1544-1553

25. Kraft M, Glanz H, von Gerlach S, Wisweh H, Lubatschowski $H$, Arens C (2010) Optical coherence tomography: significance of a new method for assessing unclear laryngeal pathologies. HNO 58(5):472-479

26. Kobler JB, Chang EW, Zeitels SM, Yun SH (2010) Dynamic imaging of vocal fold oscillation with four-dimensional optical coherence tomography. Laryngoscope 120(7):1354-1362

27. Burns JA, Kim KH, Kobler JB, deBoer JF, Lopez-Guerra G, Zeitels SM (2009) Real-time tracking of vocal fold injections with optical coherence tomography. Laryngoscope 119(11):2182-2186

28. Ridgway JM, Ahuja G, Guo S, Su J, Mahmood U, Chen Z, Wong B (2007) Imaging of the pediatric airway using optical coherence tomography. Laryngoscope 117(12):2206-2212

29. Ridgway JM, Su J, Wright R, Guo S, Kim DC, Barretto R, Ahuja G, Sepehr A, Perez J, Sills JH, Chen Z, Wong BJ (2008) Optical coherence tomography of the newborn airway. Ann Otol Rhinol Laryngol 117(5):327-334

30. Young D, Morton R, Bartley J (2010) Therapeutic ultrasound as treatment for chronic rhinosinusitis: preliminary observations. J Laryngol Otol 124(5):495-499

\begin{tabular}{|c|c|c|c|c|c|c|}
\hline Large 405 & 2051 & $\mathbf{x x x x}$ & Dispatc & 5.12 & & of Pages: 9 \\
\hline Journal & Article & MS Code & LE $\square$ & TYPESET $\square$ & CP $\square$ & DISK $\square$ \\
\hline
\end{tabular}

